\title{
ECRH system, microwave diagnostics and experimental results in the EAST tokamak
}

\author{
F.K. Liu, H.D. Xu, X.J. Wang, D.J. Wu, M.H. Li, J. Zhang, Y. Liu, T. Zhang, Q. Zhang, \\ Y.P. Zhao, J.G. Li and the EAST team
}

Institute of Plasma Physics, Chinese Academy of Sciences, Hefei, China, mhli@ipp.ac.cn

Electron cyclotron resonance heating (ECRH), as a highly efficient and controllable heating tool, has been widely used in tokamak magnetic confinement devices [1]. Usually, the EC power can be injected as narrow Gaussian beams, which gives rise to highly localized power deposition. Consequently, ECRH and electron cyclotron current drive (ECCD) have been expolied to an ideal candidate for local transport studies and for the control of various magnetohydrodynamics (MHD) instabilities occurring in tokamak plasmas. Unlike other RF heating techniques, EC wave can propagate in vacuum and the coupling is insentitive to the parameters at plasma edge, which suggests that the antenna can be located far away from the plasma. This advantage makes ECRH an attractive scheme for a thermonuclear device like ITER, in which, the launcher cannot be close to the plasma in order to avoid the material erosion and thermal damage.

EAST is a fully superconducting tokamak with a major radius of $R_{0}=1.90 \mathrm{~m}$ and a minor radius of $a=$ $=0.45 \mathrm{~m}$. The EC system will consist of a $4 \mathrm{MW}$ continuous wave $(\mathrm{CW})$ at $140 \mathrm{GHz}$ (second harmonic of the extraordinary mode) for heating and current drive applications $[2,3]$. In line with the long pulse operational capability of EAST, it was designed for a pulse length up to 1000 s. Benefitting from a pulse step modulator (PSM) type of power supply system it has a capability of fast modulation frequency up to $1 \mathrm{kHz}$. There are four gyrotrons produced by two different venders, namely, No1.and No.3 are provided by Russian company GYCOM, and the other two by CPI, USA. The specific parameters are shown in

Table 1. Specific parameters of gyrotrons

\begin{tabular}{|l|l|l|}
\hline & No.1 and No.3 & No.2 and No.4 \\
\hline Vender & Gycom & CPI \\
\hline Type & Diode & Diode \\
\hline Cavity mode & $\mathrm{TE}_{22.8}$ & $\mathrm{TE}_{28.7}$ \\
\hline Max. output power & $1 \mathrm{MW}$ & $900 \mathrm{KW}$ \\
\hline Pulse Length & $100 \sim 1000 \mathrm{~s}$ & $100 \sim 1000 \mathrm{~s}$ \\
\hline Output beam & Gaussian beam & Gaussian beam \\
\hline Collector type & Depressed & Depressed \\
\hline $\begin{array}{l}\text { Collector power } \\
\text { limit }\end{array}$ & $1.1 \mathrm{MW}$ & $1.8 \mathrm{MW}$ \\
\hline Cathode voltage & $-46 \mathrm{kV}$ & $-59 \mathrm{kV}$ \\
\hline Beam current & $43 \mathrm{~A}$ & $40 \mathrm{~A}$ \\
\hline Body voltage & $+25 \mathrm{kV}$ & $+22 \mathrm{kV}$ \\
\hline Filament power & $1000 \sim 1200 \mathrm{~W}$ & $200 \sim 250 \mathrm{~W}$ \\
\hline
\end{tabular}

Table 1. The EC power will be launched from four mirrors located in the same port at low field side. In order to satify the physical need of changing power deposition in a large region, the launch angles can be continuously varied with range of over 30 degree in poloidal direction and \pm 25 degree in toroidal as shown in Fig. 1. At present,
No.1 and No.2 gyrotron systems have been installed and the layout is shown in Fig. 2. However, only No.1 system has been used for plasma experiments.

Figure 3 shows a typical waveform of long pulse and high electron temperature discharge with ECRH. The magnetic field on the axis was set to be $2.5 \mathrm{~T}$, in order to guarantee the EC power absorbed in the central region. The EC power of $0.4 \mathrm{MW}$ was injected at $t=3 \mathrm{~s}$ and turned off at $102 \mathrm{~s}$. The central electron temperature measured by Thomson scattering was high as $T_{\mathrm{e} 0}>4.5 \mathrm{keV}$ during the EC heating phase. The contribution of ECRH to electron temperature can be found by comparison between pulse \#59892 and pulse \#59891 in which the plasma parameters and other RF heating power were the same. As shown in Fig. 4, the electron temperature is lowered by $\sim 1.2 \mathrm{keV}$ in the core region $(\rho<0.25)$ for pulse \#59891 without ECRH.

Long pulse $\mathrm{H}$-mode discharge with the combination of lower hybrid (LH), ion cyclotron (IC) and EC waves heating has been obtained in EAST. Typical traces of an H-mode discharge with ECRH $(t=1.3-31.4 \mathrm{~s})$ and ECRH $(t>31.4 \mathrm{~s})$ are illustrated in Fig. 5. It can be seen that when the EC power of about $0.3 \mathrm{MW}$ was turned off at $31.4 \mathrm{~s}$, the H-mode confinement phase was still maintained. However, the plasma stored energy $\left(W_{\mathrm{MHD}}\right)$ was decreased gradually from $145 \mathrm{~kJ}$ to $103 \mathrm{~kJ}$, which indecates that ECRH is very important for high performance plasma. Besides, the loop voltage ( $\left.V_{\text {loop}}\right)$ was increased slightly after EC power switched off, passibly resulted from the decrease in electron temperature which affects LH current drive efficiency significantly [4].

Microwave (MW) techniques such as quasi-optical reflector / lens, heterodyne detection, and lossless transmission line, are applied widely in plasma diagnostics on EAST, including the electron cyclotron emission (ECE) temperature measurement and the reflectometry for density and density fluctuation measurement. The ECE diagnostics consists of two radiometer systems and a Michelson interferometer [5]. The typical characteristics of the diagnostics are listed in Table 2. Thanks to the good spatial and temporal resolution, it can be used for investigation on MHD instabilities in addition to providing conventional temperature profiles. A new quasi-optical antenna with better poloidal resolution has been developed recently, which can be used for $T_{\mathrm{e}}$ fluctuation measurement in next campaign. The X-mode polarized Q-, V- and $\mathrm{W}$-band reflectometries allow to measure the density profile from plasma edge to core [6]. These reflectometries featured by a high time resolution of $50 \mu$ s demonstrate the ability for study of pedestal physics on EAST as shown in Fig. 6. The systems are currently being upgraded to couple/decouple Q-, V- and W-band based on 
quasi-optical method, and to use double-ridged horns with a broad band of 33-110 GHz for launcher and receiver.

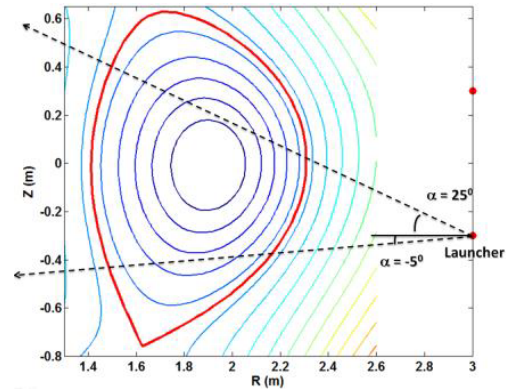

Fig. 1. EAST magnetic equilibrium and poloidal steering capability for the EC launchers at $Z=-0.3 \mathrm{~m}$. The red thick curve represents the lost closed magnetic surface

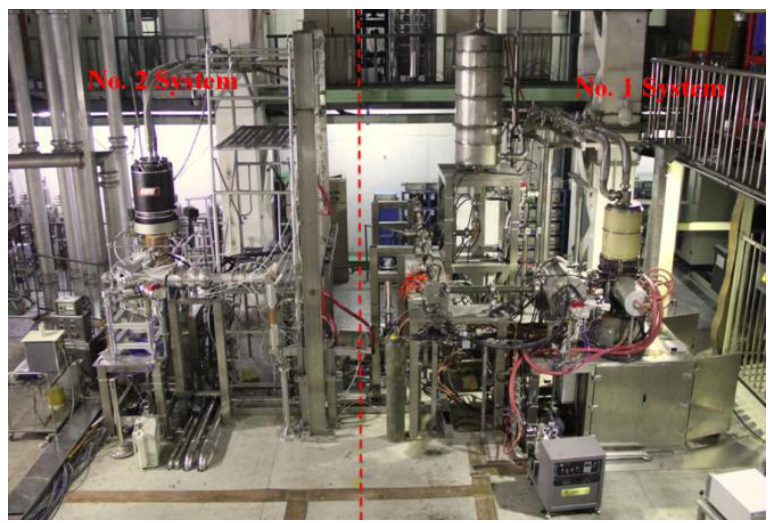

Fig. 2. The installed No.1 and No.2 gyrotron systems

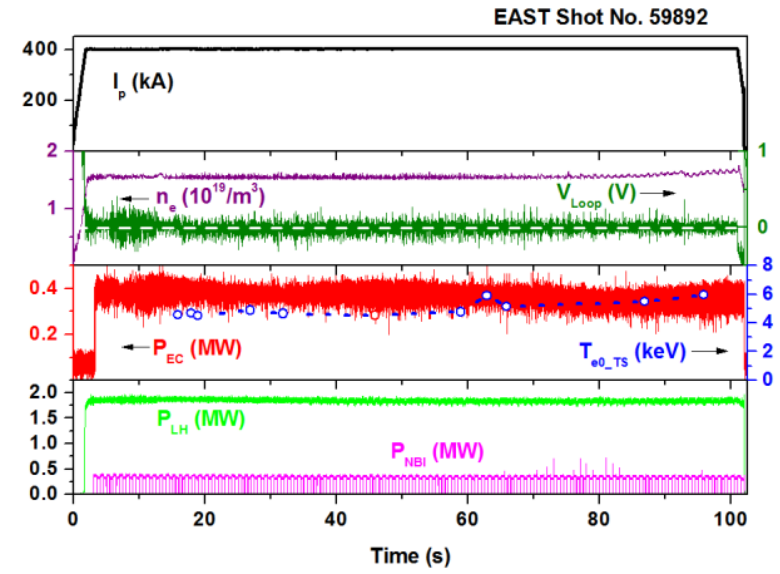

Fig. 3. Typical waveform of long pulse and high electron temperature discharge with ECRH

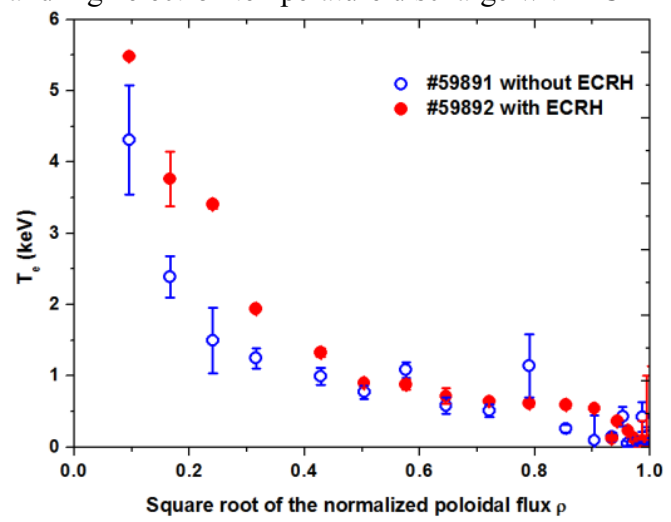

Fig. 4. Comparison of electron temperature profiles with ECRH and without it

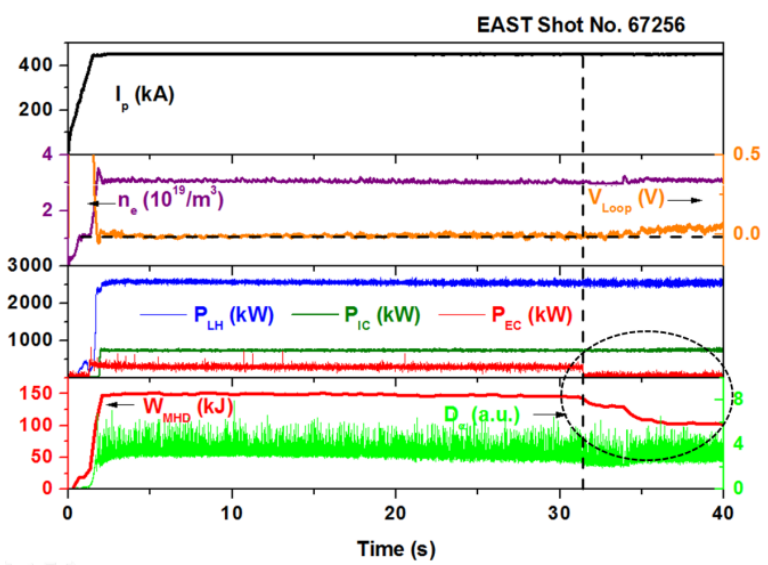

Fig. 5. Time evolutions of an H-mode discharge with ECRH $(t=1.3-31.4 \mathrm{~s})$ and without ECRH $(t>31.4 \mathrm{~s})$

Table 2. Details of ECE diagnostics

\begin{tabular}{|l|c|c|c|}
\hline \multicolumn{1}{|c|}{ Name } & $\begin{array}{c}\text { 32-channel } \\
\text { radiometer }\end{array}$ & $\begin{array}{c}\text { 16-channel } \\
\text { radiometer }\end{array}$ & $\begin{array}{c}\text { Michelson } \\
\text { interferometer }\end{array}$ \\
\hline $\begin{array}{l}\text { Frequency } \\
\text { coverage }\end{array}$ & $104-168 \mathrm{GHz}$ & $97-120 \mathrm{GHz}$ & $80-500 \mathrm{GHz}$ \\
\hline $\begin{array}{l}\text { Spectral reso- } \\
\text { lution }\end{array}$ & $0.5 \mathrm{GHz}$ & $0.2 / 0.5 \mathrm{GHz}$ & $2.8 \mathrm{GHz}$ \\
\hline $\begin{array}{l}\text { Temporal } \\
\text { resolution }\end{array}$ & $2.5 \mathrm{us}$ & $2.5 \mathrm{us}$ & $30 \mathrm{~ms}$ \\
\hline
\end{tabular}

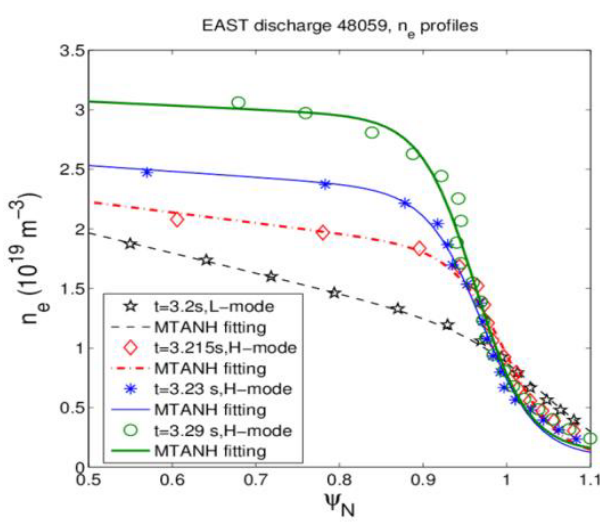

Fig. 6. An example of electron density profiles measured by fast frequency sweeping reflectometry

\section{References}

1. ITER Physics Expert Group on Energetic Particles, Chapter 6: Plasma auxiliary heating and current drive Nucl. Fusion 1999. V. 39, No. 12. P. 2495-2539.

2. Wang X. J. et al. Progress of high power and long pulse ECRH system in EAST Fusion Eng. Des. 2015. V. 96-97. P. $181-186$.

3. Xu H. D. et al. Development and Preliminary Commissioning Results of a Long Pulse $140 \mathrm{GHz}$ ECRH System on EAST Tokamak Plasma Sci. Technol. 2016. V. 18, No. 4. P. 442-448.

4. Li M. H. et al. Study on lower hybrid current drive efficiency at high density towards long-pulse regimes in Experimental Advanced Superconducting Tokamak Phys. Plasmas 2014. V. 21. P. 062510-1- 062510-9.

5. Liu Y. et al. A Michelson Interferometer for Electron Cyclotron Emission Measurements on EAST Plasma Sci. Technol. 2016. V. 18, No. 12. P. 1148-1154.

6. Qu H. et al. Q-Band X-Mode Reflectometry and Density Profile Reconstruction Plasma Sci. Technol. 2015. V. 17, No. 12. P. $985-990$ 